\title{
A SOCIEDADE DE RISCO NA VISÃO DE ULRICH BECK E SUAS CONEXÕES COM O DIREITO E MEIO AMBIENTE
}

\section{Celciane Malcher Pinto ${ }^{1}$}

\section{RESUMO}

Diante do atual cenário de crise ambiental destaca-se a Teoria da Sociedade de risco de Ulrich Beck que trata dos novíssimos riscos ambientais típicos da pós-modernidade. Neste contexto, a presente pesquisa busca tecer uma abordagem transdisciplinar referente aos contornos da sociedade qualificada pelo risco bem como busca discutir os desafios do Direito Ambiental nesta atual conjuntura. Com isso, percebeu-se a insuficiência da ciência em gerir tais riscos e a transdisciplinaridade surge como exigência na gestão dos riscos pelo Direito Ambiental. A metodologia utilizada no estudo trata-se de pesquisa bibliográfica e qualitativa.

Palavras Chave: Pós-modernidade; Problemas ambientais; Sociedade de risco; Teoria; Construção Social.

\section{THE RISK SOCIETY IN THE VIEW OF ULRICH BECK AND ITS CONNECTIONS WITH LAW AND THE ENVIRONMENT}

\begin{abstract}
Faced with the current scenario of environmental crisis, Ulrich Beck's Risk Society Theory stands out, dealing with the brand new environmental risks typical of modernity. In this context, the present research seeks to weave a transdisciplinary approach referring to the outlines of society qualified by risk as well as seeking to discuss the challenges of Environmental Law in this current conjuncture. With this, it was noticed the insufficiency of science to manage such risks and transdisciplinarity emerges as a requirement in risk management by Environmental Law. The methodology used in the study is bibliographic and qualitative research.
\end{abstract}

Keywords: Postmodernity; Environmental problems; Risk society; Theory; Social Construction.

\section{Introdução}

O marco teórico norteador das reflexões propostas neste estudo pauta-se na teoria social sobre o risco desenvolvida por Ulrich Beck. Esse sociólogo se destacou na Sociologia Ambiental ao abordar os riscos ecológicos na sociedade contemporânea questionando as instituições modernas e o papel da ciência frente à complexidade ambiental.

\footnotetext{
${ }^{1}$ Mestre em Direito Ambiental pelo Programa de Pós-Graduação em Direito Ambiental da UEA. Pós- graduada em Direito Penal e Processo Penal. Advogada. E-mail: celcymalcher@hotmail.com
} 
Tal construção teórica é importante na medida em que suscita discussões sobre os novos riscos globais e de graves consequências que auxiliam no processo de procura de novas alternativas para um sistema jurídico mais adaptado ao dano ambiental atual, principalmente no que se refere a sua responsabilização e reparação.

Desta forma, inicialmente será feito uma breve abordagem sobre contornos da sociedade qualificada pelo risco dando destaque as obras de Ulrich Beck e complementarmente também serão tratadas alguns pontos dos estudos do sociólogo Anthony Giddens que também teoriza sobre o risco atual sem haver, contudo, a pretensão de esgotar o tema. Depois deste contato inicial serão discutidos os desafios e as perspectivas sobre o papel do Direito Ambiental nesta sociedade de risco.

\title{
2. Um olhar sobre o risco na obra de Ulrich Beck
}

O sociólogo alemão Ulrich Beck durante a formulação de seu conceito de sociedade de $\operatorname{risco}^{2}$ a partir da análise sobre a transformação da modernidade acabou por entrelaçar assuntos que tradicionalmente eram tratados de forma desconexa: o natural e o social, conforme explica:

\begin{abstract}
O mundo social e o mundo natural estão, hoje, completamente infundidos pelo conhecimento humano reflexivo; mas, tal não conduz a uma situação em que coletivamente, somos mestres de nosso próprio destino. Pelo contrário, o futuro parece-se cada vez menos com o passado e tornou-se assustador nalguns de seus aspectos mais básicos (...). A noção de "risco" é hoje central na cultura moderna, precisamente porque grande parte do nosso pensamento é do tipo "se... então". Temos, em muitos aspectos da nossa vida, quer individual quer coletiva, métodos para construir potenciais futuros, sabendo, no entanto, que essa mesma construção pode impedi-los de chegar a acontecer. Novas áreas de imprevisibilidade são muitas vezes criadas pelas próprias tentativas que visam o seu controle. (BECK, 1997, p. 12).
\end{abstract}

A discussão sobre o teor de poluição e da destruição da natureza, segundo Beck, ocorreu tradicionalmente sobre a predominância do olhar das ciências naturais causando com isso um déficit do pensamento social quanto às questões ambientais. Houve no decorrer da modernidade uma tendência em analisar a problemática ambiental como uma questão essencialmente relacionada à natureza e a tecnologia. Ao se dar pouca (ou em certos casos

\footnotetext{
${ }^{2}$ Embora este trabalho eleja a perspectiva construtivista de Ulrich Beck para explicar a sociedade de risco, existem outras abordagens sociais que relacionam o risco e as questões ambientais, são elas: (1) a análise culturalista de Mary Douglas e Aeron Wildavski; (2) a abordagem sistêmica de Niklas Luhmann e; (3) a interpretação fenomenológica de Anthony Giddens (MATTEDI, 2002, p. 129-151).
} 
nenhuma) importância às consequências "sociais, políticas e culturais" dos riscos ambientais as pessoas tendem a ver o meio ambiente como um mero dispositivo orgânico ao não vislumbrar seu sentido social e cultural (BECK, 2011, p. 29-30).

Assim, em meio a uma sociedade que é caracterizada pela busca intensa por inovações tecnológicas, mas desacompanhada de um método que garanta a previsão das consequências dos riscos das suas decisões, surge a sociedade de risco:

No sentido de uma teoria social e de um diagnóstico de cultura, o conceito de sociedade de risco designa um estágio da modernidade ${ }^{3}$ em que começam a tomar corpo as ameaças produzidas até então no caminho da sociedade industrial. (BECK, 1997, p. 17)

Durante a década de 80, Ulrich Beck tece suas proposições teóricas a partir do exame sobre a mudança ocorrida no interior da própria modernidade ao passar da sociedade industrial clássica do século XIX (Primeira Modernidade ou modernidade simples) para a sociedade de risco do século XXI (Segunda Modernidade). A primeira, que havia dissolvido a sociedade agrária estamental que a antecedia, agora é dissolvida pela atual modernidade marcando com isso um processo de mutação. (BECK, 2011, p. 12-13).

Esta nova configuração da modernidade do XXI marcada pelo intenso avanço tecnológico e dos processos produtivos faz surgir riscos (ambientais, sociais, políticos, econômicos, etc.) imprevisíveis que fogem ao controle das instituições e designa uma nova etapa dentro da modernidade em que as ameaças estão a revela-se como fruto indesejado da sociedade industrial que "(...) levanta a questão da autolimitação daquele desenvolvimento, assim como da tarefa de predeterminar os padrões (...) atingidos até aquele momento, levando em conta as ameaças potenciais." (BECK, 1997, p. 17).

Beck ao analisar as transformações ocorridas na sociedade industrial verifica que o dinamismo desta destrói seus próprios fundamentos fazendo surgir uma nova sociedade (a de risco). A esta fase em que um tipo de modernização transforma outro tipo é chamada de modernização reflexiva que se refere "a possibilidade de uma (auto) destruição criativa de toda uma época: a da sociedade industrial. O sujeito da autodestruição criativa não é a revolução, nem a crise, mas a vitória da modernização ocidental” (BECK, 1997, p. 13).

\footnotetext{
${ }^{3} \mathrm{O}$ conceito de modernização adotado pelo autor de forma generalizante significa "o salto tecnológico de racionalização e a transformação do trabalho e da organização" englobando, além disso, mudanças sociais e de estruturas de poder e controle (BECK, 2011, p. 23).
} 
O termo "reflexivo" do conceito não significa "reflexão" e sim é empregado no sentido de "autoconfrontação" precisamente entre as bases da modernização e suas consequências. Conforme explica Ulrich Beck (1997, p. 17) a modernidade reflexiva significa "auto confrontação com os efeitos da sociedade do risco, efeitos esses que não podem ser resolvidos nem assimilados pelo sistema da sociedade industrial, nem medidos pelos modelos institucionalizados desta última”.

Esta modernização da modernização, como é chamada pelo autor, requer uma nova forma de encarar os riscos da atualidade como se pode perceber depois da ocorrência de certos desastres como: as duas guerras mundiais, o massacre de judeus em Auschwitz, hecatombe de Nagazaki, o acidente nuclear de Chernobyl entre outros. Se antes os perigos e as implicações dos atos de violência podiam ser delimitados a certos grupos e espaços, desde Chernobyl rompe-se o com a ideia de distanciamento entre aqueles que causavam os danos e aqueles que os sofriam (BROUWERS; PEREIRA, 2011, p. 43).

$\mathrm{Na}$ sociedade moderna atual as ameaças não podem ser determinadas pela ciência e estão além da capacidade de percebê-las. Neste contexto, podem-se determinar três áreas de referências que marcam a modificação trazida pela sociedade de risco (Beck, 1997, p. 17-18)

Primeiro, há o relacionamento da sociedade industrial moderna com os recursos da natureza e da cultura, sobre cuja existência ela é construída, mas que estão sendo dissipados no surgimento de uma modernização amplamente estabelecida. Isto se aplica à natureza não humana e à cultura humana em geral, assim como aos modos de vida cultural específicos [...].

Segundo, há o relacionamento da sociedade com as ameaças e os problemas produzidos por ela, que por seu lado excedem as bases das ideias sociais de segurança [...]. Isto se aplica a componente da sociedade, como os negócios, o direito ou a ciência, mas se torna um problema particular na área da ação política e da tomada de decisões.

Terceiro, as fontes de significado coletivas e específicas de grupo (por exemplo, consciência de classe ou crença no progresso) na cultura da sociedade industrial estão sofrendo de exaustão, desintegração e desencantamento. Estas deram apoio às democracias e às sociedades econômicas ocidentais no decorrer do século XX e sua perda conduz à imposição de todo esforço de definição sobre indivíduos; é isso que significa o conceito do "processo de individualização".

A sociedade industrial se despede da história não por meio de uma revolução ou outro fato de caráter político, mas em silenciosa normalidade contrariando o mito de que tal sociedade significava o ápice da modernidade com suas formas de vida, trabalho, democracia e progresso científico, etc., ou seja, contraria a ideia de que a história social teria alcançado uma sociedade completamente moderna. (BECK, 2011, p. 13-14). 
Em sua teoria o autor explica os paradigmas sobre a distribuição de riquezas e de riscos que marcaram a passagem no processo de transformação moderna. Enquanto que na sociedade industrial (ou de classes) a preocupação era em como tornar legítima a distribuição desigual da riqueza socialmente produzida, na sociedade de risco o problema refere-se a como as ameaças e riscos devem ser redistribuídos de modo a serem considerados aceitáveis e capazes de suportar a lógica da modernização atual. Na medida em que os riscos avançam, as promessas de segurança são reforçadas para que as pessoas se sintam tranquilizadas quanto aos efeitos colaterais negativos causados pelo "progresso". (BECK, 2011, p. 24).

Beck acabou ampliando suas reflexões sobre a sociedade de risco resultando no conceito de sociedade de risco global que "corresponde à sociedade de risco pensada até as suas últimas consequências. (...) seus desafios são os perigos produzidos pela civilização que não podem ser delimitados socialmente nem no tempo nem no espaço". A sociedade de risco global tem as seguintes características conforme sintetiza Brouwers e Pereira (2011, p. 46):

a) inter-relação entre dois conflitos, duas lógicas de distribuição: a distribuição de bens e males - enquanto que na sociedade industrial os embates se travavam em torno da distribuição das riquezas advindas da produção de bens, na sociedade global de risco, procura-se equacionar os efeitos globais, dentre os quais os impingidos ao meio ambiente e às sociedades periféricas, da radicalização da produção industrial, baseada na globalização do capital;

b) debilitação dos fundamentos do cálculo do risco, haja vista a impossibilidade de serem compensados, financeiramente, danos decorrentes do agravamento do nível de desemprego, do subemprego e da pobreza;

c) debilitação das burocracias e do domínio da economia clássica e redefinição das fronteiras e frentes de batalha da política contemporânea em face do desencadeamento de uma dinâmica de mudanças culturais e políticas em função da explosividade social dos riscos financeiros globais;

d) colapso da instituição Estado-nação;

e) emergência do conceito de globalização responsável como tema público e político de alcance mundial em virtude da reflexibilidade causada pelo risco; e

f) surgimento de novas opções: protecionismo nacional e regional, instituições transnacionais e democratização.

Sobre a importância do conceito de sociedade de risco no processo de transformação sociopolítica do século XXI defende Beck:

O conceito de sociedade de risco expressa a acumulação de riscos - ecológicos, financeiros, militares, terroristas, bioquímicos, informacionais - que tem uma presença esmagadora hoje em nosso mundo. Na medida em que o risco é vivido como algo onipresente, só há três reações possíveis: negação, apatia e transformação. A primeira está fortemente inscrita na cultura moderna, mas ignora o risco político da negação; a segunda se rende a uma veia niilista no pósmodernismo; a terceira destaca a questão levantada por minha teoria sobre a 
sociedade de risco: de que modo a antecipação de uma multiplicidade de futuros produzidos pelo homem, e de suas consequências, afeta e transforma as percepções, as condições de vida e as instituições das sociedades modernas? (BECK, 2010, p. 361)

A hipótese levantada por Beck é de que a incerteza produzida pela sociedade industrial não resulta necessariamente na instalação do caos e na ocorrência da catástrofe. Pode haver nessa "incerteza incalculável" uma oportunidade para novo, e neste sentido pergunta: "existe também uma função esclarecedora nos riscos globais? E que forma ela assumiria?” (BECK, 2010, p. 361).

Sustenta Beck que a consciência dos riscos globais cria novas oportunidades para "futuros alternativos, modernidades alternativas" onde as barreiras de interesses e conflitos nacionais devem ser rompidas. Isto deriva do fato de que um dos efeitos desses riscos é a “criação de um mundo comum", embora essa ideia não soe muito atrativa aos mais egoístas ou àqueles que têm a ilusão de criar seu "mundinho" longe dos riscos. Todos partilham o mesmo mundo e disso não se tem como fugir (BECK, 2010, p. 364).

Além da projeção no tempo e da capacidade de controle, os novos riscos ainda tem a capacidade de abrangência incalculável quanto ao número de pessoas afetadas conforme comenta Bahia (2012, p. 59) “(...) os novos riscos, em virtude de sua indeterminação e dificuldade de avaliação científica, são passíveis apenas de uma "avaliação probabilística" e têm a potencialidade de atingir um número indeterminado de pessoas".

\section{O risco sob a ótica de Anthony Giddens}

$\mathrm{Na}$ mesma linha, a tese de Anthony Giddens converge em muitos aspectos com a teoria de Ulrich Beck, uma vez que esses sociólogos vão além da análise sobre a percepção do risco para abordarem especificamente os pontos característicos dos riscos contemporâneos:

Beck e Giddens, inicialmente de forma paralela e, depois, a partir de um diálogo aberto em publicações diversas, transformaram substancialmente o debate sobre os riscos - em especial, os de caráter ambiental e tecnológico -, ao apresenta-los como centrais para entender a sociedade contemporânea. A forma pela qual esses dois sociólogos passaram a considerar os riscos é tão original quanto polêmica [...]. Ainda que reconheçam que sempre houve riscos, Beck e Giddens consideram que os atuais são objetivamente diferentes. Para ambos a sociedade contemporânea caracteriza-se pela radicalização dos princípios que orientam o processo de modernização industrial, o que marcaria a passagem da sociedade moderna para a sociedade da alta modernidade, segundo Giddens, ou para a sociedade de risco ou da modernização reflexiva, segundo Beck. Com este argumento ambos os teóricos 
também se distanciam das análises pós-modernas, na medida em que afirmam que ainda estamos na pós-modernidade (GUIVANT, 1998, p. 17).

Para Giddens, assim como para Beck, no decorrer da modernidade existe dentro dela uma transformação: a primeira é chamada de modernização simples marcada pela produção de riscos calculáveis pela sociedade industrial. A segunda, cunhada de alta modernidade, refere-se ao período moderno em que há a produção de uma classe avançada de riscos caracterizados por serem imprevisíveis em toda sua extensão e que levam a um estado de insegurança social.

Giddens ao tratar sobre os riscos peculiares da sociedade hodierna, assim os define:

Risco não é o mesmo que infortúnio ou perigo. Risco se refere a infortúnios ativamente avaliados em relação a possibilidades futuras. A palavra só passa a ser amplamente utilizada em sociedades orientadas para o futuro - que veem o futuro precisamente como um território a ser conquistado ou colonizado. O conceito de risco pressupõe uma sociedade que tenta ativamente romper com o passado - de fato, a característica primordial da civilização industrial moderna. (GIDDENS, 2007, p. 33)

A ideia de risco ${ }^{4}$ sempre esteve atrelada a modernidade, mas atualmente toma novos contornos. Para demostrar tal afirmação, estabelece a diferença entre dois tipos de riscos: o externo e o fabricado. O primeiro refere-se às externalidades como a natureza. Já o risco fabricado diz respeito ao risco criado como resultado da ação humana a partir de seu conhecimento sobre o mundo e cujos níveis são cada vez mais incertos. Estes por serem imprevisíveis envolvem situações sobre as quais pouco ou nada se sabe, como por exemplo, as reais consequências das mudanças climáticas do planeta (GIDDENS, 2007, p. 37-38).

Os riscos fabricados criam muitas vezes um clima político de alarmismo $\mathrm{x}$ acobertamento. Quando há a descoberta de um risco por parte de uma autoridade política ou científica e existe o interesse em divulga-lo para o público, faz-se um estardalhaço se preciso for. Mas quando se conclui que não passavam de um alarme falso os anunciantes são taxados de alarmistas. Já quando não existe interesse em divulgar tais riscos e estes mais tarde vêm à tona diz-se que houve um acobertamento de situações que deveriam ter sido divulgadas podendo eventualmente ser evita-los. Como exemplo, expõe Giddens (2007, p. 39):

\footnotetext{
${ }^{4}$ Segundo o autor a noção de risco ainda não existia para as grandes civilizações anteriores ao período moderno uma vez que os acontecimentos estavam ligados à ideia de destino, sorte ou vontade divina. Embora este pensamento ainda exista na atualidade é tido geralmente como superstições e não como explicação aceitável para certos eventos, diferente, portanto, do risco que marca a dinâmica da modernidade contemporânea. (GIDDENS, 2007, p. 34).
} 
Suponha, contudo que as autoridades avaliem inicialmente que um risco não é muito grande, como o fez o governo britânico no caso da carne bovina contaminada. Nesse caso, o governo começou a declarar: temos o respaldo de cientistas aqui: não há risco significativo e quem quiser pode continuar a comer carne bovina sem nenhum temor. Em situações como essa, se os acontecimentos tomam um rumo diferente como de fato tomaram - as autoridades são acusadas de acobertamento - como realmente foram.

Defende o autor que na chamada sociedade pós-tradicional as ações individuais e os acontecimentos globais estão correlacionados e que "Esta extraordinária - e acelerada relação entre as decisões do dia- a- dia e os resultados globais, juntamente com seu reverso, a influência das ordens globais sobre a vida individual, compõem o principal tema da nova agenda" (GIDDENS, 1997. p. 74).

Neste contexto, para Giddens a modernização reflexiva e seus riscos imprevisíveis levam a um estado de desconfiança sobre o próprio conhecimento científico produzido, ou seja, a ciência perde seu papel de produtora e legitimadora de verdades infalíveis.

\begin{abstract}
A ciência perdeu boa parte da aura de autoridade que um dia possuiu. De certa forma, isso provavelmente é resultado da desilusão com os benefícios que, associados à tecnologia, ela alega ter trazido para a humanidade [...]. Mas a ciência pode - e na verdade deve - ser encarada como problemática nos termos de suas próprias premissas. O princípio "nada é sagrado" é em si um princípio universalizado, que não isenta nem a aclamada autoridade da ciência (GIDDENS, 1997. p. 109).
\end{abstract}

Sobre a nova natureza dos riscos e sobre os questionamentos que envolvem a própria ciência comenta Bahia (2012, p. 58):

(...) nenhuma instituição encontra-se preparada para lidar com o pior acidente possível e diversos especialistas voltam-se para a única possibilidade que lhes resta: negar a existência dos riscos. Assim, o dogma da infalibilidade da ciência termina sendo desmascarado a cada novo acidente e a estabilidade política das sociedades de risco passa a depender do "não pensar nas coisas".

Para Giddens o conceito de sociedade de risco abarcaria mais do que apenas novos riscos e perigos a humanidade, mas refere-se também “[...] a novas relações entre sistemas de conhecimento leigos e peritos, num contexto em que a estimação dos riscos é, em grande parte, imponderável” (GUIVANTE, 1998, p. 21).

Diante da insuficiência da Ciência para a compreensão dos novos riscos, a confiança nas respostas dos peritos e especialistas para enfrentar a conflitualidade dos novos espaços 
sociais mostra-se insuficientes. Este quadro de dependência x insuficiência dos chamados sistemas peritos é explicado por Giddens (1991, p. 30):

\begin{abstract}
Por sistemas peritos quero me referir a sistemas de excelência técnica ou competência profissional que organizam grandes áreas dos ambientes material e social em que vivemos hoje. A maioria das pessoas leigas consulta "profissionais" advogados, arquitetos, médicos, etc., - apenas de modo periódico ou irregular. Mas os peritos influenciam muitos aspectos do que fazemos de uma maneira contínua. Ao estar simplesmente em casa, estou envolvido num sistema perito, ou numa série de tais sistemas, nos quais deposito minha confiança. Não tenho nenhum medo específico de subir escadas da moradia, mesmo considerando que sei que em princípio a estrutura pode desabar. Conheço muito pouco os códigos de conhecimento usados pelo arquiteto e pelo construtor no projeto e construção da casa, mas não obstante tenho "fé" no que eles fizeram. Minha fé não é tanto neles, embora eu tenha que confiar em sua competência, como na autenticidade do conhecimento perito que eles aplicam - algo que não posso, em geral, conferir exaustivamente por mim mesmo.
\end{abstract}

Nesta sociedade destradicionalizada o conhecimento perito é constantemente revisado frente às novas informações que se apresentam. Este conhecimento especializado atualmente exerce grande influência sobre o modo de vida de todos como, por exemplo, do consumidor que busca a maior quantidade possível de informações sobre um produto antes de comprá-lo. Percebe-se que o conhecimento leigo ao mesmo tempo em que se mostra insuficiente para certas demandas do dia-a-dia gera também um ceticismo acerca do conhecimento científico. Segundo Guivante (1998, p. 21) "Este processo de construção de nossas biografias, distante das influencias da tradição, é denominado por Giddens de "reflexividade", com um sentido mais pessoal e intencional que o referido ao termo por Beck".

No que se refere às questões sobre os riscos ambientais e do impacto do industrialismo sobre o meio ambiente ganham destaque nas obras de Beck e Giddens visto que "para estes sociólogos as sociedades altamente industrializadas [...] enfrentam riscos ambientais e tecnológicos que não são meros efeitos colaterais do progresso, mas centrais e constitutivos dessa sociedade" (GUIVANTE, 1998, p. 17).

Tratando sobre o perfil de risco específico à modernidade Giddens destaca o risco derivado do meio ambiente criado, ou natureza socializada, que se refere à infusão de conhecimento humano no meio ambiente físico que ocasionam diversos perigos ecológicos:

A simples quantidade de riscos sérios ligados à natureza socializada é bem assustadora: a radiação a partir de acidentes graves em usinas nucleares ou do lixo atômico; a poluição química nos mares suficiente para destruir o plâncton que renova boa parte do oxigênio na atmosfera; um "efeito estufa" derivado dos 
poluentes atmosféricos que atacam a camada de ozônio, derretendo parte das calotas polares e inundando vastas áreas; a destruição de grandes áreas de floresta tropical que são uma fonte básica de oxigênio renovável; e a exaustão de milhões de áreas de terra fértil como resultado do uso intensivo de fertilizantes artificiais. (GIDDENS, 1991, p. 114)

Assim, a sociedade de risco descrita por Beck e Giddens inaugura uma nova da modernidade em que é necessário conviver com uma nova qualidade de riscos que colocam o planeta em estado de alerta, onde o clima de insegurança é verificado especialmente diante da complexidade da problemática ambiental que requer, por sua vez, uma reflexão sobre as bases do Direito Ambiental e seu papel neste contexto, conforme se verá a seguir.

\section{O Direito Ambiental na sociedade de risco: desafios e perspectivas}

A modernização reflexiva descrita por Ulrich Beck e Anthony Giddens trás a tona um turbilhão de novas e complexas situações ambientais imprevisíveis e incontroláveis. Neste panorama, os efeitos negativos e os desdobramentos resultantes deste modelo de modernização inserem a natureza e as sociedades atuais em um cenário de crise que reclama uma adequada postura do Direito Ambiental, inclusive reavaliando seus próprios fundamentos frente aos diversos desafios próprios da sociedade de risco:

\footnotetext{
Neste quadro particular de caracterização da temática ambiental (globalizada e imprevisível), o Direito é posicionado em condição de crítica: crítica de sua eficácia e do grau de sua funcionalidade na organização de respostas especializadas (jurídicas) e adequadas para atender as qualidades especiais dos efeitos negativos da crise ecológica nas sociedades contemporâneas. Estes se expressam na forma de riscos inseguráveis e que são originados de processos de decisão desenvolvidos em espaços institucionais de acentuado déficit democrático, com poder de vitimar gerações em uma escala espacial e temporal de difícil determinação para ciência e pelos especialistas (AYALA, 2011, p. 18).
}

Diante de uma sociedade qualificada pelo risco onde os efeitos tecnológicos tomam a forma de acontecimentos naturais de grande vulto e capacidade de proliferação pelo mundo, percebe-se a insuficiência do conhecimento científico em gerir tais riscos ecológicos e em consequência questiona-se a capacidade regulatória do Direito Ambiental para tratar tais situações, conforme atenta Viegas (2007, p. 66) "Todo o conjunto de normas jurídicas, das quais se esperam respostas para a chamada "crise ambiental", passa a ser objeto de reflexão: também o Direito Ambiental é questão para o próprio Direito Ambiental”. 
Traçando a relação entre meio ambiente e a atual modernidade, a sociedade de risco é definida por Leite (2015, p.113) como "aquela que, em função de seu contínuo crescimento econômico, pode sofrer a qualquer tempo as consequências de uma catástrofe ambiental." Verifica-se no caminho de transição da sociedade industrial para a sociedade de risco que os problemas estão continuamente se agravando, no entanto, o sistema jurídico se mostra ultrapassado para tratar das novas situações que se apresentam.

O modelo de responsabilização tradicional do Direito Ambiental cuja configuração é baseada no ato, dano e no nexo causal entre estes, mostra-se insuficiente frente ao perfil dos novos riscos ambientais ao se considerar, por exemplo, a sua invisibilidade e a obscuridade que paira em certos casos sobre as fontes emissoras de poluição. Nesta sociedade de risco caracterizada pelo consumo em massa e pela desregrada utilização de seus recursos ambientais comenta Milaré (2011, p.1.247) que “(...) haveria de exigir um tratamento da matéria com viés de um novo Direito, e não pelos limites da ótica privada tradicional".

Frente aos impactos negativos do "progresso" sobre o meio ambiente, típicos da sociedade de risco, interessante observar uma tendência do Estado e das instituições privadas em esconder suas ações irresponsáveis a fim de manter a sociedade não ciente sobre a realidade dos riscos ecológicos. Tal conjuntura refere-se a outro conceito importante desenvolvido por Beck chamado de irresponsabilidade organizada, que indica:

O movimento circular entre a normalização simbólica e as ameaças constantes e destruições materiais. A administração do Estado, a política, a gestão industrial e comercial e a pesquisa negociam os critérios que determinam o que se considera "saudável e seguro", com o resultado que o buraco na camada de ozônio aumenta, as alergias se difundem massivamente, etc. (BECK, 2006, p.50) (tradução nossa) ${ }^{5}$

Nota-se que esta irresponsabilidade organizada coloca as instituições modernas e o próprio Direito Ambiental numa situação intrigante: ao mesmo tempo em que através da Ciência é possível (ou não) obter subsídios para a compreensão da crise ambiental somada a uma inquestionável expansão da produção de normas de proteção ambiental verifica-se por outro lado que tais instituições tendem a abafar a gravidade dos problemas ecológicos que em consequência acabam por dificultar o controle e responsabilização dos danos.

\footnotetext{
5 No original: "El concepto de "irresponsabilidad organizada" indica el movimiento circular entre la normalización simbólica y las permanentes amenazas y destrucción materiales. La administración del Estado, la política, la gestión industrial y la investigación negocian criterios que determinan que ha de considerarse 'racional y seguro': con el resultado de que el agujero en la capa de ozono aumenta, las alergias se extienden massivamente, etcétera".
} 
Nessa tentativa de tornar invisíveis os danos ecológicos e seus efeitos através da manipulação de certos instrumentos (como, por exemplo, o Estudo de Impacto AmbientalEIA) busca-se também convencer a sociedade leiga de que tais danos estão controlados. Neste panorama, pontua Leite e Belchior (2012, p. 17) que "a irresponsabilidade organizada acaba transformando o Estado em faz de conta, em Estado-fantoche, que só dá publicidade aos fatos científicos de acordo com seus interesses".

Sobre importância de que o Direito Ambiental exerça sua real função de proteção ao meio ambiente e não represente apenas um papel figurativo no ordenamento jurídico pátrio, ressalta-se:

\begin{abstract}
A necessidade de afastar o Direito Ambiental da racionalidade da irresponsabilidade organizada e desvinculá-lo da intenção do exercício de uma função meramente simbólica. Apenas com o reconhecimento dos riscos da atualidade, o que pressupõe que sejam eles trazidos a público, o Direito Ambiental poderá ser alicerçado sobre novas bases que viabilizarão a efetiva utilização de seus instrumentos como forma de salvaguardar o meio ambiente ecologicamente equilibrado para as gerações presentes e futuras (LEITE; AYALA, 2010, p. 117).
\end{abstract}

Além da precariedade de políticas de gestão para o enfrentamento dos riscos globais e do anonimato ligado à ideia de irresponsabilidade organizada, tais riscos têm a capacidade de atingir um número indeterminado de pessoas que podem alcançar até mesmo as gerações futuras. Sobre a necessidade de uma regulação jurídica ambiental na sociedade de risco comprometida com o futuro ressalta Ayala (2011, p. 27) que "dependerá da ênfase de práticas e alternativas para a gestão dos riscos, que considerem a distribuição compartilhada de deveres e responsabilidades entre as gerações".

Nesse sentido, diante do avançado nível tecnológico e de suas consequências sobre a qualidade ambiental, seja como efeitos negativos ligados as decisões de uma classe restrita cunhada de "ecomáfia", seja pela acumulação dos efeitos negativos dos comportamentos ambientais individuais irresponsáveis, permite verificar as seguintes características da sociedade de risco:

\footnotetext{
${ }^{6}$ Este termo refere-se ao poder de decisão dos grandes conglomerados industriais e seus grandes impactos sobre o meio ambiente como, por exemplos, a contaminação de recursos hídricos por poluição industrial histórica de complexos industriais de difícil identificação; falhas nos sistemas de controle de segurança de usinas nucleares e indústrias químicas, entre outros (AYALA, 2011, p. 21).
} 
a) elevada desconfiança que é cultivada pelos cidadãos em relação á eficácia e à capacidade de enfrentamento dos riscos de diversas ordens, pelos peritos, especialistas e cientistas, e;

b) o grande potencial que possuímos de submetermos o desenvolvimento da vida de todas as gerações a restrições impertinentes e estados de desfavorabilidade inconsequentes (AYALA, 2011, p. 21).

Sobre a questão dos erros, fraudes, equívocos e verdades que envolvem os especialistas pontua Ulrich Beck que existem duas visões, ou racionalidades, sobre a percepção dos riscos atuais: a científica (representada por especialistas) e a social (população leiga). A ciência, valendo-se da tradicional autoridade a ela conferida, coloca-se como a confiável fonte válida no processo de entendimento dos riscos e para isso conta com seus especialistas que tem a pretensão de especificamente estipulá-los. Por outro lado, a população percebe os riscos, mas suas opiniões são geralmente desconsideradas por serem tidas como “irracionais" pelo mundo científico. Essa colisão no campo da percepção dos riscos entre especialistas e leigos é assim ilustrada:

\begin{abstract}
A "irracionalidade" da "percepção pública" do risco que seja "desviante" consistirá no fato de que aos olhos dos técnicos, a maioria da população ainda se comporta como estudantes do primeiro semestre de engenharia, ou ainda pior. São de fato ignorantes, mas mostram boa vontade, esforçam-se, sem, contudo ter a mínima ideia. Nessa imagem, a população é formada por um bando de aspirantes de engenheiro isolados, que ainda não dispõem dos conhecimentos necessários. Basta empanturrá-la com detalhes técnicos para que ela então se associe ao ponto de vista e à avaliação dos especialistas sobre o manejo técnico e, portanto, sobre como os riscos não representam qualquer risco. Protestos, temores, crítica e resistência no espaço público são todos um mero problema de informação. (BECK, 2011, p. 69)
\end{abstract}

Segundo Beck, esta visão dogmática da ciência está errada. A racionalidade técnicocientífica "satisfeita consigo mesma" e ao mesmo tempo "embaraçada da sua crença no progresso" está equivocada sobre o que considera "irracionalidade" da percepção popular dos riscos e mais: deveria considerá-la e averiguá-la como base de seu estudo. Assim, segundo o autor, as ciências não estão preparadas para os crescentes riscos e ressalta ainda o fato de que estas tem grande parcela de culpa no surgimento e proliferação de tais riscos. As ciências, neste aspecto, são consideradas "as madrinhas legitimadoras de uma poluição e contaminação industrial em escala mundial do ar, da água, dos alimentos etc., assim como da decriptação generalizada com ela associada e da morte de plantas, animais e seres humanos" (BECK, 2011, p.71). 
Essa desconfiança que envolve cientistas e especialistas nas sociedades contemporâneas faz sentido quando se verifica o perfil inédito dos riscos capazes que são de projetar seus efeitos no tempo somado a realidade de que estão envolvidos pela globalidade e alto poder destrutivo. Neste contexto, especialmente o Direito Ambiental é questionado quando constantemente mostra-se dependente das asserções técnico-científicas de peritos e especialistas para pautar suas decisões.

É possível verificar também um déficit regulatório para tratar dos danos e conflitos ambientais que tipicamente são marcados pela imprevisão e vultuosidade na sociedade de risco. Neste sentido, as normas de Direito Ambiental são destacadas por Viegas (2007, p. 77):

Com efeito, a perplexidade desta disciplina é duplamente qualificada: por um lado, o
arsenal legislativo já existente não dá conta dos problemas ambientais de graves
consequências, por tudo de inédito que representam e que se contrapõe ao
tradicional esquema de responsabilização jurídica fundada no ato, no dano e no nexo
causal entre ambos; por outro lado, as normas de Direito Ambiental não são capazes,
como é da própria natureza do Direito (que anda sempre passos atrás da dinâmica
das relações sociais), de dar conta de todos os problemas ambientais, mesmo porque
vários deles ainda sequer figuram na arena social, quiçá no palco judicial.

Diante disso, o Direito ambiental tem em vista novos problemas que exigem certas modificações no tocante:

(a) a forma de identificação dos novos conflitos que qualificam a proteção jurídica a do ambiente nas sociedades de risco; (b) a forma de compreensão e entendimento prático e comum dessas novas relações por todos os cidadãos; e (c) o modo pelo qual são definidas as opções, e pelo qual são orientados os julgamentos das alternativas possíveis para a tomada de decisões a partir de problemas de risco. (AYALA, 2011, p. 21)

Percebe-se a dificuldade de compreensão adequada dos conflitos resultantes dos efeitos negativos do risco global - cuja complexidade é evidenciada quando se relaciona com problemas de outras ordens como as crises sociais, financeiras, políticas, etc. - que por sua vez dificultam a escolha de alternativas para a devida proteção ambiental numa sociedade que não dispõe de segurança técnica e científica para que sejam tomadas decisões no caso concreto, neste sentido:

O problema suscitado ao Direito Ambiental nas sociedades de risco não é, portanto, apenas o de compreensão inadequada da nova ordem de problemas que se estabelecem a partir de composições e relações, mas o de tomar decisões a partir da qualidade diferenciada desses conflitos. Este importa considerar sinteticamente, o 
problema de como superar da melhor forma possivel, o conjunto de imprevisões, incertezas e indefinições que tipificam os processos em que decisões e escolhas devem ser realizadas para a concretização dos objetivos de proteção do ambiente nas sociedades de risco. (AYALA, 2011, p. 29).

Como alternativa para a gestão de riscos na sociedade contemporânea é sugerido um novo padrão de democracia no processo de tomada de decisões: a abordagem transdisciplinar. Esta abordagem se justifica pelo fato de que a perspectiva disciplinar da ciência mostrar-se incapaz de ser uma solução para o enfrentamento dos novos problemas ambientais calcados na instabilidade cognitiva e imprevisibilidade. Assim, é proposta a elaboração de um conhecimento científico diferenciado sobre o ambiente a partir da transdisciplinaridade no Direito Ambiental:

A compreensão transdisciplinar do ambiente, mais do que a disponibilidade de comunicação e diálogo entre diversos saberes disciplinares, deve permitir e possibilitar o desenvolvimento de uma nova racionalidade social, econômica, política e jurídica, que considere efetivamente o ambiente como fator de organização e definição da nova qualidade do conhecimento que se procura, o saber ambiental. ${ }^{7}$ (AYALA, 2011, p. 31).

Neste sentido, a ideia transdisciplinar é também abordada na teoria da complexidade de Edgar Morin que aborda sobre a necessidade de um pensamento complexo que considera a incompletude e a incerteza no processo de compreensão da realidade através de seu contexto. O que se busca é o que ele chama de conhecimento pertinente, ou seja, a informação deve ser considerada de forma contextualizada, a perigo de esvaziar-se o seu sentido, conforme explica:

(...) para conhecer, não podemos isolar uma palavra, uma informação; é necessário ligá-la a um contexto e mobilizar o nosso saber, a nossa cultura, para chegar a um conhecimento apropriado e oportuno da mesma. (...) Ora, hoje vivemos uma época de mundialização, todos os nossos grandes problemas deixaram de ser particulares para se tonar mundiais: o da energia e, em especial, o da bomba atômica, da disseminação nuclear, da ecologia, que é o da nossa biosfera, o dos vírus, como a Aids, imediatamente se mundializam. Todos os problemas se situam em um nível global e, por isso, devemos mobilizar a nossa atitude não só para os contextualizar, mas ainda para os mundializar, para os globalizar (MORIN, s/d, p. 02-03).

\footnotetext{
${ }^{7}$ O saber ambiental é assim definido por Leff (2001, p. 168): "é afim com a incerteza e a desordem, com o campo do inédito, do virtual e dos futuros possíveis, incorporando a pluralidade axiológica e a diversidade cultural na formação do conhecimento e na transformação da realidade".
} 
Logo, o pensamento complexo pressupõe mudar a maneira de ver o meio ambiente e por consequência suscita repensar o Direito Ambiental através de bases democráticas nos processos de tomada de decisões e na busca de um conhecimento ainda indisponível. Sobre essa reforma comenta Morin:

\begin{abstract}
A reforma do pensamento permitirá frear a regressão democrática que suscita, em todos os campos da política, a expansão da autoridade dos experts, especialistas de todos os tipos, estreitando progressivamente a competência dos cidadãos, condenados à aceitação ignorante das decisões dos pretensos conhecedores, mas de fato praticantes de uma inteligência cega, posto que parcelar e abstrata, evitando a globalidade e a contextualização dos problemas. $\mathrm{O}$ desenvolvimento de uma democracia cognitiva só é possível numa reorganização do saber, a qual reclama uma reforma do pensamento capaz de permitir não somente a separação para conhecer, mas a ligação do que está separado (MORIN, 2003, p. 26).
\end{abstract}

Assim, dada a complexidade da nova qualidade de problemas, a transdisciplinaridade surge como exigência na gestão dos riscos pelo Direito Ambiental. Para este fim, são apontados três os instrumentos: a participação; o desenvolvimento do significado jurídico da precaução e, principalmente, a proteção do direito à informação ambiental de qualidade e dos deveres de produção da informação ainda indisponível. A responsabilidade para a produção desse conhecimento deve ser compartilhada entre todos os atores desse processo (AYALA, 2011, p. 32-33).

\title{
5. Conclusões
}

Diante de todas as considerações aqui trazidas, pode-se concluir que dentre dos diversos efeitos negativos à que estão expostas as sociedades contemporâneas, os resultantes da crise ambiental ganham especial destaque uma vez que afetam o cotidiano de todos ao redor do mundo: os riscos ecológicos transcendem fronteiras e cruzam diferentes ambientes e culturas.

Percebeu-se que diante da sociedade de risco diversos são os obstáculos encontrados pelo Direito Ambiental e isto fica evidente pelas demandas ambientais cada vez mais inéditas e carentes de respostas à altura da natureza dos novíssimos riscos globais. Essa complexidade ambiental aliada à ausência de políticas de gestão dos riscos típica da irresponsabilidade 
organizada colocam o Direito e suas formas tradicionais de lidar com o dano em situação delicada e aponta para um novo paradigma.

O pensamento cartesiano que predominou na modernidade encontra-se em crise. As respostas absolutas, cujo rigor científico era baseado em quantificações e redução da complexidade, já não são mais buscadas. Embora essa visão não tenha sido abolida de todo, na sociedade atual de risco uma concepção sistêmica do conhecimento científico tem se mostrado mais adequada.

Um exemplo típico da insuficiência do modelo cartesiano está no trato do meio ambiente. As múltiplas dimensões (físicas, sociais, éticas, morais, econômicas, jurídicas, etc.) da natureza requerem um modo de pensar global no processo de compreensão da realidade. Neste sentido, a racionalidade que despreza valores subjetivos como a espiritualidade e os sentimentos, por exemplo, não resultará em um conhecimento pertinente sobre o bem em questão.

O paradigma emergente pautado na visão holística, na abordagem sistêmica e na interdisciplinaridade tem seus reflexos na área jurídica e mais especificamente no Direito Ambiental. Com efeito, esta mudança trouxe a incorporação de uma nova hermenêutica sobre a juridicidade do dano ambiental e deu novas funções à responsabilidade civil através da observância de princípios estruturantes como o da dignidade da pessoa humana, a proteção da sadia qualidade de vida e a reparação integral do meio ambiente.

\section{REFERÊNCIAS}

AYALA, Patryck de Araújo. Transdisciplinaridade e os novos desafios para a proteção jurídica do ambiente nas sociedades de risco. Entre direito, ciência e participação. Revista de Direito Ambiental. São Paulo: Revista dos Tribunais, nº 61, p. 17-35, jan.-mar./2011.

BAHIA, Carolina Medeiros. Dano Ambiental e nexo de causalidade na sociedade de risco. In: Heline Silvini Ferreira; Maria Leonor Paes Cavalcanti Ferreira. (orgs.). Dano ambiental na sociedade de risco. São Paulo: Saraiva, 2012, p. 55- 80.

BECK, Ulrich. Sociedade de risco: rumo a uma outra modernidade. Tradução de Sebastião Nascimento. São Paulo: Editora 34, 2011.

Diálogo com Ulrich Beck. Sociedade de risco: rumo a uma outra modernidade. Trad. Bruno Simôes. São Paulo, 2010, p. 361- 376. Entrevista. XXI, 2006.

La Sociedad del Riesgo. Segunda Edición. Trad. Jesús Alborés Rey. Madrid: Siglo Revista de Direito e Sustentabilidade | e-ISSN: 2525-9687 | Encontro Virtual | v. 7 | n. 1 | 
A reinvenção da política: rumo a uma teoria da modernização reflexiva. In: GIDDENS, Anthony, BECK, Ulrich, LASH, Scott. Modernização reflexiva: política, tradição e estética na ordem social moderna. São Paulo: Unesp, 1997, 11 -71.

BROUWERS, Silvana do Prado; PEREIRA, Reginaldo. Sociedade de risco e racismo Ambiental na Globalização. Revista de Direito Ambiental. São Paulo: Revista dos Tribunais, no 61, p. 37-74, jan.-mar./2011.

GIDDENS, Anthony. Mundo em descontrole. Tradução Maria Luiza X. de A. Borges - $6^{\mathrm{a}}$ Ed. - Rio de Janeiro: Record, 2007.

A vida em uma sociedade pós-industrial. In: GIDDENS, Anthony, BECK, Ulrich, LASH, Scott. Modernização reflexiva: política, tradição e estética na ordem social moderna. São Paulo: Unesp, 1997, p. 73-133.

As consequências da modernidade. São Paulo: Unesp, 1991.

GONÇALVES, Carlos Alberto. Responsabilidade civil. 10 ed. São Paulo: Saraiva, 2007.

GUIVANT, Julia. A trajetória das análises de risco: da periferia ao centro da Teoria Social. Revista Brasileira de Informações Bibliográficas- ANPOCS. n. 46, p. 3-38, 1998.

LEFF, Enrique. Epistemologia ambiental. Trad. Sandra Valenzuela. São Paulo: Cortez, 2001.

LEITE, José Rubens Morato, AYALA, Patryck de Araújo. Dano Ambiental: do individual ao coletivo extrapatrimonial. 7. ed. rev., atual. e ampl.. São Paulo: Revista dos Tribunais, 2015 .

José Rubens Morato, BELCHIOR, Germana Parente Neiva. Dano ambiental na sociedade de risco: uma visão introdutória. In: Heline Silvini Ferreira; Maria Leonor Paes Cavalcanti Ferreira. (orgs.). Dano ambiental na sociedade de risco. São Paulo: Saraiva, 2012, p. 13-54.

MATTEDI, Marcos Antônio. As interpretações sociológicas das dinâmicas sociais de construção do risco na sociedade moderna. Revista Grifos 13. Chapecó: Argos, 2002.

MILARÉ, Édis. Direito do ambiente: a gestão ambiental em foco: doutrina jurisprudência, glossário. 7. ed. rev., atual. e reform. São Paulo: Revista dos Tribunais. 2011.

MORIN, Edgar. KERN, Anne Brigitte. Terra-Pátria. Tradução por Paulo Azevedo Neves da Silva. - 4. ed. - Porto Alegre: Sulina, 2003.

Da necessidade de um pensamento complexo. Trad. de Juremir M. da Silva). Disponível em: <http://edgarmorin.org.br/imgul/15072009173315605188650. pdf $>$. Acesso em: 13 de março 2021.

TRENNEPOHL, Terence Dorneles. Direito Ambiental. 4. Ed. Bahia: Juspodivm. 2009. 
VIEGAS, Thaís Emília de Sousa. Do silêncio à crise: Uma perspectiva do Direito Ambiental a partir da Teoria da Sociedade de Risco. Dissertação (Mestrado em Direito). Universidade Federal de Santa Catarina. Florianópolis, 2007. Disponível em: <www.egov.ufsc.br/portal/sites/default/files/anexos/33917-44602-1-PB.pdf.>. Acesso em: 10 de março 2021. 